\title{
EXAME NACIONAL DE CURSOS E POLÍTICA DE REGULAÇÃO ESTATAL DO ENSINO SUPERIOR
}

\author{
ALFREDO MACEDO GOMES \\ Programa de Pós-Graduação em Educação da Universidade Federal de Pernambuco \\ alf1964@terra.com.br
}

\begin{abstract}
RESUMO
Análise da política de avaliação para a educação superior formulada pelo Ministério da Educação e Cultura - MEC - na gestão Paulo Renato Sousa, com especial ênfase sobre o Exame Nacional de Cursos - ENC. O artigo discute: I. os princípios, objetivos e características da política de avaliação para o ensino superior; 2. o contexto de formulação e implementação do Exame Nacional de Cursos e a concepção de seu papel dentro do sistema de ensino superior brasileiro; 3. a avaliação como o principal instrumento de coordenação e controle empregado pelo MEC; e 4. as relações estratégicas entre a política de avaliação e a lógica de regulação estatal. Este trabalho é produto de pesquisa realizada entre 1997 e 2000, em que foram entrevistados atores responsáveis pela formulação de políticas para o ensino superior no nivel federal.

POLITICASEDUCACIONAIS-AVALIAÇÃO-POLITICASPÚBLICAS-ENSINOSUPERIOR
\end{abstract}

\section{ABSTRACT}

THENATIONAL EXAMINATION OF COURSESAND THESTATEREGULATIONPOLICYIN BRAZILIAN HIGHER EDUCATION. This work analyses the assessment policy for higher education formulated by the Ministry of Education and Culture - MEC - in the Paulo Renato Sousa's term, with especial reference to the National Examination of Courses. The following policy aspects are treated in this article: I. principles, aims, and methodological features of the Cardoso government assessment policy; 2. the context of the policy's formulation and implementation, and the role played by it in brasilian higher education system; 3. the assessment as the MEC's core policy instrument of co-ordination and controlling; and 4. strategic relations between this policy and the logic of state regulation. EDUCATION POLICIES - ASSESSMENT - PUBLICPOLICIES - HIGHEREDUCATION

Este artigo representa a adaptação do capítulo sexto de tese de doutorado (Gomes, 2000) realizada na Universidade de Bristol, Inglaterra, no período de 1997-2000, com suporte financeiro da Coordenação de Aperfeiçoamento do Pessoal de Nível Superior - Capes. Foi apresentado na 24a Reunião Anual da Associação Nacional de Pós-Graduação e Pesquisa em Educação, (GT Política de Educação Superior), realizada em Caxambu (MG), de 7 a I I de outubro de 200 I. 
A linguagem do Programa de Avaliação Institucional das Universidades Brasileiras - Paiub (Brasil, 1993, 1994) não é a mesma daquela do projeto educacional do governo do presidente Fernando Henrique Cardoso. Este governo tem não apenas uma política diferente de avaliação da educação superior quando esta é comparada com o Paiub, como também vem implementando-a com instrumentos e estratégias políticas diferenciadas. Este artigo dedica-se à análise da mais visível e também criticada iniciativa de política educacional implantada pelo Ministério da Educação - MEC - na gestão do ministro Paulo Renato Sousa. A hipótese explorada é a de que a política de avaliação desse governo ilustra os novos mecanismos pelos quais a relação entre governo e os setores do ensino superior tem sido reestruturada. Mais importante, porém, em termos dessa hipótese, é a observação de que a política de avaliação, formulada e estrategicamente implementada pelo MEC, não representa simplesmente uma mudança no relacionamento entre este governo e os setores do ensino superior. Representa uma reestruturação significativa dos mecanismos e instrumentos tradicionais e burocráticos que têm historicamente caracterizado a relação do Estado com a educação superior no Brasil.

O objetivo deste artigo é analisar alguns aspectos da política de avaliação para a educação superior formulada pelo MEC, na gestão do ministro Paulo Renato Sousa', tomando como objeto de análise o Exame Nacional de Cursos ENC - e suas rupturas e contrastes em relação ao Paiub. Os seguintes aspectos são abordados:

I. Os princípios, objetivos e características metodológicas da política de avaliação para o ensino superior.

2. O contexto de formulação e implementação, e o papel desempenhado pelos principais atores.

I. Gostaria de enfatizar que os procedimentos, instrumentos e mecanismos constituintes da política de avaliação para o ensino superior do Governo FHC incorporam, além do Exame Nacional de Curso, que é analisado neste artigo, os seguintes elementos: I. a análise dos principais indicadores de desempenho global do sistema nacional de ensino; 2. a avaliação do desempenho individual das instituições de ensino superior (aqui se encontra - Paiub que foi redefinido pela atual administração); e 3. a Avaliação das Condições de Oferta de Cursos (Brasil, 1996). Em outro artigo (Gomes, 200 I), que representa a parte II da análise Política de avaliação para o sistema de ensino superior do Governo FHC, esses procedimentos da política de avaliação são tratados detalhadamente. 
3. A avaliação como o principal instrumento político de coordenação e controle usado pelo MEC.

4. A relação estratégica entre a política de avaliação e a lógica de regulação estatal.

Os dados analisados neste artigo são de várias fontes. Parte foi coletada em entrevistas abertas realizadas com pessoas que ocupam posições consideradas estratégicas no MEC e com membros da Câmara de Educação Superior do Conselho Nacional de Educação. Outra parte consiste da legislação da educação superior, com especial referência para aquela produzida durante o Governo Fernando Henrique Cardoso (que se iniciou em 1995). Também foram analisados documentos de política educacional tais como planos e programas, e informações selecionadas de artigos, entrevistas e discursos publicados na imprensa sobre o ensino superior no Brasil.

\section{CONTRASTES ENTRE O PAIUB E O EXAME NACIONAL DE CURSOS}

Ao analisar uma determinada política, plano ou programa educacional, é metodologicamente recomendável que se inicie com a descrição do contexto de formulação da política educacional acompanhada da caracterização dos principais atores envolvidos em tais processos. Aqui, porém, adotou-se o caminho oposto. Inicia-se com apresentação das características de duas iniciativas de políticas de avaliação, primeiro, o Paiub, formulado e implementado durante o Governo Itamar (1993-1994) e, segundo, o ENC, elaborado e implementado pelo Governo Fernando Henrique Cardoso. Espera-se, pois, que a comparação apresentada adiante contribua para o entendimento da atual política de avaliação do MEC e seu papel regulador em relação aos diferentes setores do ensino superior brasileiro. O quadro I, construído com base em documentos analisados e entrevistas, reúne uma síntese das principais informações sobre essas duas iniciativas.

Diante da omissão intencional das informações sobre os contextos de formação e implementação das duas iniciativas apresentadas no quadro I, não é difícil deduzir que uma política de avaliação concebida e implementada sob os princípios básicos do Paiub não foi formulada pelo governo, e sim pelas universidades federais ou por uma comissão que as representava. Globalidade (ou seja, todos os aspectos da vida de uma universidade devem ser, em princípio, avaliados), não comparabilidade, respeito à identidade institucional, não premiação ou 


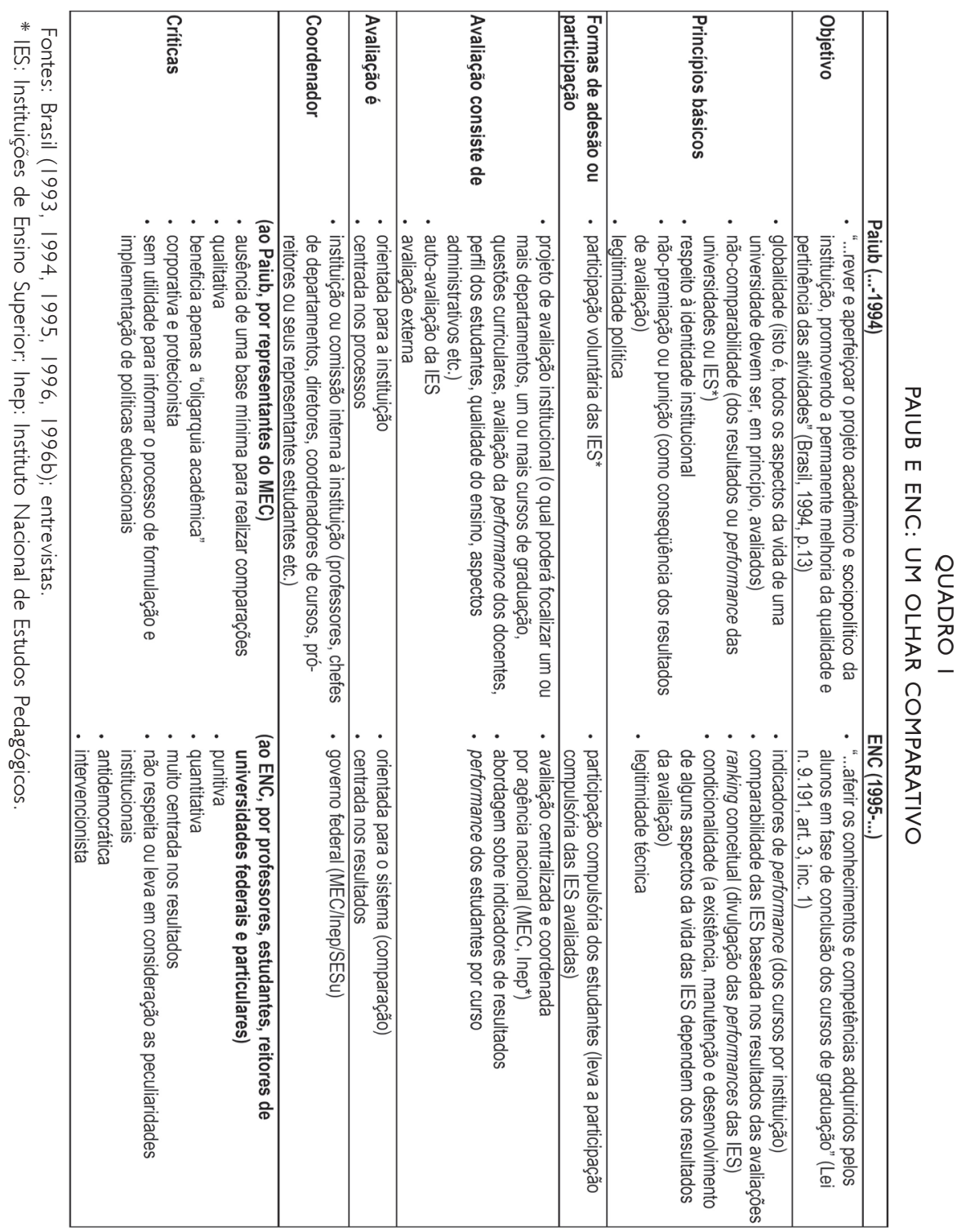


punição, participação voluntária e legitimidade política (Brasil, 1994, 1993) são princípios que não fazem usualmente parte da agenda governamental para o ensino superior, pelo menos recentemente. Isso porque, primeiro, estes princípios são uma declaração de autonomia e, como tal, constituem uma proclamação antiintervencionista por parte das universidades; segundo, eles elevam a autoavaliação à abordagem central e única do processo de avaliação; terceiro, tais princípios básicos anunciam as missões e objetivos institucionais e, assim, a plena liberdade da instituição para realizá-los, dado que a avaliação das suas atividades é um produto de tais princípios e não um antecedente.

O contrário, todavia, pode ser deduzido dos "princípios" subjacentes ao ENC (Quadro I). Eles sugerem um grupo de mecanismos de controle a serem exercidos por agências externas às universidades e às instituições de ensino superior não universitárias. Os "princípios": indicadores de resultados, comparação das performances das instituições, ranking dos cursos em forma de conceitos, condicionalidade no uso dos resultados da avaliação e participação compulsória dos estudantes são instrumentos de uma política de avaliação formulada centralmente e implementada de cima para baixo. Isso porque, primeiro, exprimem o ímpeto para medir e, assim fazendo, para comparar resultados medidos; segundo, "princípios" tais como participação compulsória e condicionalidade no uso dos resultados anunciam um elevado grau ou potencial de controle e regulação estatal; terceiro, a comparação pelos resultados leva, com raras exceções, a sua publicação em formato de ranking ; e, por último, do ponto de vista da política do Governo FHC para o ensino superior, a publicação dos resultados da avaliação deve engendrar uma reação "saudável" por parte dos agentes do mercado do ensino superior (estudantes-consumidores, pais e outros clientes) em relação às instituições de ensino superior (leia-se "qualidade dos serviços prestados") e, como conseqüência, deve gerar práticas modernas de competição entre as IES.

Ambos os grupos de "princípios" do Paiub e do ENC ("Provão"), como se pode concluir, respondem a diferentes objetivos e usam para tanto distintos procedimentos de avaliação. Mais importante, todavia, é que eles revelam projetos educacionais, estilos e práticas de formulação e implementação de políticas que são essencialmente divergentes.

\section{O CONTEXTO POLÍTICO DE FORMULAÇÃO DO PAIUB}

Paiub resultou de uma parceria entre a Secretaria de Ensino Superior do MEC e alguns setores das universidades brasileiras. Em 1993, a SESu criou 
a Comissão Nacional de Avaliação cuja principal "função [era] conduzir politicamente o processo de avaliação institucional” (Brasil, 1994, p.5). A Comissão Nacional, coordenada pela SESu e formada por representantes de quatro associações nacionais de universidades (Andifes, Abraem, Anup e Abesc) ${ }^{2}$ e de quatro associações nacionais de pró-reitores (Graduação, Pesquisa e Pós-graduação, Extensão, e Planejamento e Administração), era vista como representativa e oferecia, aos olhos da comunidade acadêmica, legitimidade política ao Paiub. A primeira versão de um documento nacional sobre avaliação institucional, formulada pela Andifes, foi posteriormente discutida e melhorada, gerando o Documento Básico para Avaliação das Universidades Brasileiras (Brasil, 1993). Durante o processo decisório, o governo (gestão Itamar Franco) foi um parceiro, e as universidades, particularmente as federais, assumiram o papel de principal agente de mudança. Até 1994, o papel do MEC em relação à política de avaliação foi claramente definido como sendo o de "coordenador articulador e de agência financiadora da avaliação institucional, assumindo (...) a posição política de parceiros das universidades" (Brasil, 1996b, p. I).

Contudo, entre os princípios do Paiub, alguns são particularmente reveladores para a compreensão do papel exercido pelo MEC em relação ao processo de avaliação das universidades. São eles: respeito à identidade institucional, nãopremiação ou punição e adesão voluntária ao programa. Esses princípios significavam que o governo federal era bem-vindo como um parceiro desde que ele não estabelecesse nenhum tipo de condição como conseqüência dos resultados da avaliação. Entre 1993 e 1994, tanto as lideranças do MEC como os representantes das universidades estavam muito mais preocupados em estabelecer uma "cultura [positiva] de avaliação", como notou o ex-secretário de educação superior do MEC Rodolfo Joaquim (Brasil, 1994, p.6). O objetivo mais urgente era desfazer a idéia de avaliação como necessariamente punitiva, idéia essa associada à publicação da "lista dos improdutivos da Universidade de São Paulo" em 1988. Aí reside uma das razões da aceitação de que a parceria entre governo e universidade deveria ser realizada em observância aos princípios do Paiub. No tocante ao relacionamento entre o Governo Itamar Franco - gestão Murilo Hingel - e o ensino superior, o Paiub representou o reconhecimento consensual de que a

2. Na seqüência as siglas desdobradas: Associação Nacional dos Dirigentes das Instituições Federais de Ensino Superior, Associação Brasileira das Universidades Estaduais e Municipais, Associação Nacional das Universidades Particulares e Associação Brasileira de Escolas Católicas. 
avaliação seria necessária para elevar a qualidade das atividades acadêmicas (ensino, pesquisa e extensão) e também que o processo e procedimentos avaliativos deveriam ser conduzidos pelas próprias instituições de ensino superior. Em outras palavras, a hegemonia política do processo de formulação da política de avaliação pertencia às lideranças universitárias, os quais definiram os termos e as condições sob as quais a avaliação deveria ocorrer ${ }^{3}$.

Este era um contexto no qual as universidades (principalmente as universidades federais) tinham voz e exerciam considerável influência na formulação de políticas para o setor. A então Diretora de Políticas Educacionais do MEC, Maria José Feres, testemunhava que só era possível mudar em "parceria" com as universidades. Portanto, pode-se concluir que o papel de coordenador assumido pelo MEC/SESu no período 1993/94 parecia ser o de promotor de encontros nacionais, agitador da cultura de avaliação e financiador dos projetos de avaliação (no caso das instituições públicas), sem contudo obter dados que levassem a um acurado ou mesmo razoável diagnóstico dos problemas do sistema de educação superior ${ }^{4}$.

A ausência de informações que levassem a um diagnóstico do sistema de ensino superior brasileiro, e não especificamente de uma instituição ou departamento, foi a principal crítica dirigida ao Paiub pelas lideranças do MEC (ver

3. As palavras do então Pró-Reitor de Graduação da UFSC e membro do Comitê Assessor do Paiub, Dilvo I. Ristoff, sintetizam de forma incontestável a posição das universidades em relação ao MEC. Dizia ele: "As universidades, embora se reservem o direito da dúvida e de ficar com um pé atrás, parecem ter perdido o temor na sua relação com o MEC pois viram que este entendeu que, como diz a professora Maria José Feres, Diretora do Departamento de Políticas Educacionais do MEC, "só é possível mudar com a parceria das universidades", mesmo porque qualquer análise revelará que a continuidade de projetos de educação para o país exige organização e articulação das bases". E assim concluiu Ristoff: "E neste contexto é impossível não lembrar que os reitores e pró-reitores têm, via de regra, vida mais longa em seus cargos do que os ministros e seus assessores" (Brasil, 1994, p.7).

4. $\bigcirc$ extrato da entrevista que segue com a então responsável no MEC pelo Paiub (que se revelou sua defensora ardorosa), quando perguntada sobre as deficiências detectadas no ensino de graduação, testemunha neste sentido: "Essa é uma das coisas que eu gostaria de conseguir [...] era um dos objetivos esse ano fazer com o Comitê Assessor uma análise... várias pesquisas estão sendo feitas, vários documentos, várias análises com base no programa.[...] Logo agora, talvez para o final desse ano, se peça um relatório da instituição para que ela realmente faça... essa situação onde que ela avançou, onde não conseguiu avançar, qual foi o entrave maior para que ela não deslanchasse esse processo..." (Entrevista realizada em 27/5//998). 
Quadro I). Do ponto de vista das universidades, o Paiub ainda é visto como o paradigma de avaliação. Daí emerge a posição de que o Paiub pertence às universidades, para diferenciá-lo da política de avaliação que caracteriza a gestão do ministro Paulo Renato.

A principal responsável pelo Paiub no MEC assumira que a adesão de um grande número de instituições de ensino superior devia-se à natureza de seus princípios básicos, citando como prova que houve um aumento de 55 IES participantes em 1994/95 para aproximadamente 90 em 1996/97, e que em março de 1997, I 36 IES haviam aderido ao Paiub. Ressalte-se, porém, que baseadas nos princípios e formas de implementação do Paiub, não existiam razões para que as IES recusassem a tornarem-se "parceiros" do MEC, principalmente naqueles casos em que o governo oferecia suporte financeiro às universidades para realizar a avaliação. É importante argumentar que o significativo crescimento do número de adesões por parte das IES não se dera inteiramente por causa das qualidades dos princípios básicos do Paiub, uma vez que tal crescimento foi impulsionado por um novo fenômeno que emergira barulhento no campo do ensino superior brasileiro, o ENC, o qual foi imposto pelo ministro Paulo Renato em novembro de 1995.

\section{PROCESSO DECISÓRIO DE FORMULAÇÃO DO ENC}

O processo de formulação e implementação do ENC foi completamente diferente daquele do Paiub. As associações representativas dos diversos setores universitários, assim como outros atores do campo do ensino superior, foram excluídos da sua formulação. De fato, o Governo FHC e particularmente aqueles que conduzem o MEC sinalizavam com a sua política de avaliação que um relacionamento diferente entre o governo e os setores da educação superior estava apenas iniciando. Isto é demonstrado não só pelo conteúdo da nova política de avaliação ("Provão"), mas também pela seletividade dos agentes e dos processos decisórios liderados pelo ministro Paulo Renato Sousa. Isto pode ser interpretado como uma ruptura com o processo ascendente de consulta e parceria que tinha permeado o contexto de tomada de decisões na administração Hingel, representando uma recentralização dos mecanismos e processos decisórios. Seguindo as metas estabelecidas no Planejamento Politico-Estratégico(Brasil, 1995a), - MEC perseguia sua estratégia de reestruturar a forma de fazer política educacional assim como os instrumentos de coordenação e controle do sistema, adotando iniciativas agressivas para colocar em prática aquilo que Neave (1988) deno- 
mina Evaluative State (Estado avaliador). O ENC exerce um duplo papel nessa transformação. Em primeiro lugar, ele tornou-se o produto mais visível, como política educacional para o ensino superior, do novo estilo de fazer/gerir políticas do ministro Paulo Renato e sua equipe, e, em segundo lugar, porque o ENC foi estrategicamente planejado para ser um poderoso instrumento político para fortalecer e modernizar as funções de controle, monitoramento e coordenação do MEC. Ou, usando o discurso da moda em educação, para fortalecer a capacidade de governança sistêmica do MEC. Para reestruturar o MEC na direção de sua "progressiva transformação" em um "organismo eficaz de formulação, coordenação e acompanhamento de políticas públicas na área educacional" (Brasil, 1995a, p.4), o Ministro da Educação e equipe descartaram a adoção de formas participativas de formulação da política de avaliação, e com isso, descartaram também a concepção de que "só é possível mudar com a parceria das universidades".

Em 1996, o ENC era ao mesmo tempo o produto mais visível da abordagem centralizadora de fazer política e a primeira medida substantiva na área do ensino superior baixada pelo MEC. Tendo sido formulado durante o primeiro ano de governo (1995), o ENC não apenas focalizava uma das mais sensíveis questões do ensino superior brasileiro (a avaliação), mas o fazia trazendo consigo princípios, procedimentos metodológicos e condições que negavam essencialmente o mais elementar consenso político e técnico já alcançado na história do ensino superior por um programa nacional de avaliação, o Paiub. A reação dos defensores do programa (professores e lideranças das universidades públicas e estudantes e, em menor grau, das particulares), à primeira rodada nacional do ENC, em novembro de 1996, foi considerável, e poucos, mas muito poucos, se posicionaram em sua defesa. A presidente do Instituto Nacional de Estudos e Pesquisa em Educação - Inep -, Maria Helena G. Castro, a quem coube a "missão de colocar o 'Provão' na rua", descreve este período como "a batalha do 'Provão'”'. Já o ex-presidente da Andifes, Odilon Canto, explicando por que a Andifes era "contra o 'Provão'”, dizia: "Quando surgiu a idéia desse provão, nós nos colocamos contra a idéia de que se pudesse fazer avaliação de um sistema complexo como é uma universidade com um simples provão. E nós já vínhamos trabalhando há muito tempo no processo de avaliação institucional". Ele conclui: “Nós não somos basicamente contra o 'Provão' como um dos parâmetros para

5. A entrevista com Maria Helena Guimarães Castro foi realizada em 6 de junho de 1998. 
avaliar as universidades.[...] A forma como ele foi colocado é que está criando todo esse problema" (Canto, 1996).

É importante notar que o Paiub era o único paradigma de política de avaliação que poderia (como o foi) ser usado para contra-atacar a ofensiva política do MEC. Este paradigma deve ser entendido em termos dos seus princípios, da autonomia acadêmica para formular e realizar o projeto de avaliação institucional e, principalmente, dos processos e mecanismos decisórios de formulação das políticas públicas. Em todos esses aspectos, e particularmente no contexto de implementação do ENC, eles não poderiam ser outra coisa senão duas políticas opostas.

A parte substancial do contexto de formulação e implementação do Paiub foi justamente o que se excluiu no caso do ENC: participação, parceria e negociação entre o MEC e os setores universitários ${ }^{6}$. $\bigcirc$ que ocorrera então, como os dados sugerem, é que o ministro da Educação Paulo Renato Sousa e seus assessores mais próximos não identificaram no Paiub o poder necessário para subsidiar e equipar o MEC para exercer com "eficiência" e "eficácia" o papel de coordenador do sistema federal de ensino superior. Ou seja, o Paiub não instrumentalizava - MEC como órgão formulador de políticas para o setor, uma vez que não introduzia na dinâmica do sistema de ensino superior: I a real possibilidade de comparar o desempenho das IES (universidades públicas - federais e estaduais -, privadas e comunitárias, instituições não universitárias, cursos por instituição etc.) e 2. os mecanismos de monitoramento e punição periódicos das IES?

O contexto de formulação do ENC não foi marcado por preocupações em torno de participação, representatividade e legitimidade política, como foi o do Paiub. A principal preocupação aqui era a de implantar um instrumento de geren-

6. Não se pode deixar de lembrar que os interesses dos diversos setores das universidades brasileiras são divergentes, marcados por significativas diferenças históricas entre os setores público e privado. Contudo, em face do contexto de implantação do ENC essas divergências foram consideravelmente silenciadas. Neste sentido, falando das resistências ao ENC, Eunice Durham observava: "Ah, sim, todo mundo resistia. Aliás, a resistência no setor público foi mais organizada do que no setor privado. Acho que no Brasil o setor privado age de uma forma muito espúria, no sentido que a sua posição não se manifesta no grande debate. Ele se manifesta em termos de pressão sobre o Congresso, pressão sobre o Ministério. É uma forma diversa de resistência. Ao passo que o setor público é o setor no qual os professores se unem, se mobilizam e se manifestam. No setor privado os professores não contam" (entrevista realizada em 5 de maio de 1998).

7. Vários depoimentos de membros do MEC apontavam que o Paiub era incapaz de gerar dados que pudessem ser analisados de forma comparativa. 
ciamento político que fosse capaz de permitir ao MEC o exercício da regulação e acompanhamento do ensino de graduação o qual passa a ser referido como a prioridade central da política oficial para o ensino superior (Brasil, 1995a; Sousa, 1996, 1998). Parece ter sido o estabelecimento dessa prioridade que levou a substituição de mecanismos essencialmente burocráticos de controle da qualidade por um sistema de avaliação, o qual foi planejado para regular a expansão do ensino superior: o objetivo nuclear deste governo.

A presidente do Inep, Maria Helena G. Castro, reconstrói alguns aspectos do contexto de formulação do ENC que contribui para o entendimento do que foi dito:

Eu acho que [o ENC] foi um mérito do ministro Paulo Renato, porque internamente nós tínhamos dúvidas sobre o desenho do sistema de avaliação do ensino superior e o ministro insistia que ele queria um exame ao final dos cursos de graduação. Quer dizer, nós enquanto equipe técnica, em particular a professora Eunice e eu, e a professora Gilda Gouveia, nós tínhamos dúvidas. Nós achamos que a avaliação tinha que trabalhar com os indicadores globais de desempenho levantados pelo censo do ensino superior, com as comissões de visitas e com a avaliação institucional, certo? E com os processos de auto-avaliação interna das universidades. Mas nós tínhamos dúvidas com a obstinação do ministro Paulo Renato em relação à implantação do Exame Nacional de Cursos ao final dos cursos de graduação. E o ministro entendia que era preciso ter um exame ao final de curso que seria quase que um termômetro, um sinalizador de problemas e que esse termômetro ele se conjugaria com os outros procedimentos de avaliação, como a avaliação institucional que tem uma complexidade muito maior... Então, o ministro diz assim: não, nós temos que combinar indicadores globais da instituição como um todo com indicadores dos cursos. O que eu quero saber é: como é que está funcionando o curso $x$ ? Por que $o$ curso $x$ da faculdade tal, que não é uma faculdade conhecida, funciona bem e o mesmo curso, vamos supor de direito, de uma boa universidade funciona mal? Quais são os referentes que me permitem fazer essa afirmação? (Entrevista realizada em 6 de julho de 1998)

Esse extrato de entrevista revela, primeiro, que mesmo este seleto e poderoso grupo de atores debatia-se a respeito dos procedimentos que iriam compor o sistema de avaliação do ensino superior e, segundo, que foi a "obstinação" do ministro Paulo Renato Sousa que introduziu o ENC na agenda de atividades de estudantes, professores, departamentos e instituições de ensino superior. Ele objetivava identificar e expor, sobretudo, os indicadores de desempenho com alto grau de especificidade pelos diversos setores do sistema de ensino superior, 
focalizando sobre pequenas unidades de análises (a performance dos cursos de graduação inferida a partir da performance dos seus estudantes) em uma fase particular de transição da vida estudantil para a profissional, o ano de conclusão dos cursos. Assim, o ministro Paulo Renato Sousa queria saber "como está funcionando o curso $x$ ?" Com efeito, ele seria capaz de inferir se "o curso x " estava funcionando bem ou não mediante a aferição do desempenho dos seus estudantes, classificando o resultado do curso $x$, quando comparado com os mesmos cursos de outras IES. Se o curso x da faculdade y alcança um conceito A ou B no ranking das IES, o MEC (e a comunidade de pretendentes aos estudos superiores, assim como a sociedade em geral) raciocina que ele está funcionando bem e é melhor do que outros com desempenho inferior. Em outras palavras, a orientação básica é especificar, classificar e comparar para que ações subseqüentes sejam desencadeadas a partir dos resultados da avaliação.

As observações de Maria Helena Guimarães Castro são também reveladoras porque reafirmam que o contexto de elaboração do ENC foi altamente seletivo e, para usar um termo familiar ao Governo FCH, "esclarecido". Como apontada anteriormente, a exclusão dos principais interlocutores, tais como as lideranças universitárias, é incontestavelmente evidente. Contudo, essa exclusão foi mais um componente tático do processo decisório liderado pelo ministro Paulo Renato Sousa do que uma falha do processo político da atual gestão. É também importante notar que a "equipe técnica" pensava um modelo de avaliação que se aproximava muito do paradigma Paiub, e que seus componentes, segundo a presidente do Inep, tinham dúvidas sobre a viabilidade do ENC. Finalmente, Maria Helena Guimarães Castro revela que o ministro Paulo Renato Sousa buscou estabelecer procedimentos de avaliação que trabalhassem com indicadores de resultados institucionais e de cursos, os quais, por sua vez, distinguem sua abordagem avaliativa daquela dos membros da "equipe técnica" que propuseram um modelo mais amplo de avaliação.

Diante da reação dos estudantes e da crítica dos professores, o ministro Paulo Renato Sousa reconhecia que a política de avaliação não seria reduzida a apenas um "teste". Assim afirmava ele: "Há uma incompreensão sobre a natureza do exame. Eu já fui reitor da Unicamp e obviamente eu sei que um teste não avalia uma faculdade. Mas há um conjunto de indicadores que avalia, junto com um teste que mede o nível de aprendizagem dos estudantes" (Sousa, 1996a). Enquanto agora parece absolutamente evidente que a política de avaliação do MEC não se reduz a um teste, a Lei n. 9.13 I de 1995, que estabeleceu o ENC, não menciona nenhum outro procedimento de avaliação, exceto o ENC (Brasil, 1995). 


\section{LÓGICA E MECANISMOS DE REGULAÇÃO DO EXAME NACIONAL DE CURSOS}

Para se obter uma melhor compreensão da lógica sistêmica que caracteriza o ENC, é importante considerar que:

a. o $\mathrm{MEC}^{8}$ introduziu, como função do Conselho Nacional de Educação (especificamente a Câmara de Educação Superior);

b. o poder de deliberar sobre o reconhecimento e recredenciamento periódico de IES, inclusive universidades, com base nos relatórios e avaliações apresentados pelo MEC (Lei n. 9.13 I, de novembro de 1995). Pela primeira vez na história da educação superior brasileira, uma lei condiciona recredenciamento de IES à avaliação. Assim, a vida de uma instituição veio a depender de avaliação periódica. Contudo, até meados de 1996 o ENC (criado por esta mesma lei) era o único instrumento de avaliação indicado pelo MEC para satisfazer a condição acima. O Paiub não foi mencionado como sendo capaz de realizar tarefa tão importante;

c. em dezembro de 1996, portanto mais de um ano depois, a Lei de Diretrizes e Bases - LDB - foi promulgada e seu artigo 46 reendossa o princípio da avaliação para o ensino superior, estabelecendo a apropriada determinação legal para realizar-se a ligação não apenas entre recredenciamento de IES, mas também autorização e reconhecimento de cursos, por um lado, e regular processo de avaliação, por outro. $\bigcirc$ periódico caráter da avaliação foi ressignificado como regular. Os incisos I e 2 do artigo 46 da LDB estabelecem, respectivamente: I . a possibilidade de punição para as instituições privadas que apresentem resultados indesejáveis nas avaliações; e 2. o monitoramento e suporte financeiro para as instituições públicas;

8. Gostaria de destacar que não é minha intenção promover o MEC a uma posição de protagonista superior ao próprio Congresso Nacional. Na verdade, o MEC, como apareIho estatal diretamente subordinado ao executivo federal, conseguiu aprovar no Congresso Nacional metas e objetivos que já haviam sido anunciadas em documento de maio de 1995 (Brasil, 1995a). Por isso, pode-se argumentar que o MEC conseguiu aliados importantes no Congresso Nacional que contribuíram para o sucesso da aprovação de medidas que vieram a facilitar a implementação da política de avaliação do ensino superior, a qual, como demonstramos, foi altamente criticada pela comunidade acadêmica. 
d. a LDB determina (art. 47, inc. I) que todas as IES devem disponibilizar ou informar a todos os interessados o programa dos cursos e outros componentes curriculares (duração do curso, qualificação ou titulação dos professores, recursos, critérios de avaliação etc). Com base nessa determinação, o MEC estabeleceu a Portaria Ministerial n. 878, de julho de 1997, que especifica, entre outras coisas, as informações pertinentes que as IES devem tornar públicas mediante um catálogo. Entre outras informações, encontra-se o conceito obtido pelos cursos da IES no último "Provão";

e. por meio do Decreto n. 2.306 de agosto de 1997, que torna de direito, por um lado, a existência de instituições de ensino superior de natureza lucrativa para atuar no mercado da educação superior, e por outro, cria os centros universitários, o MEC reafirma a natureza temporária da autorização e do reconhecimento de cursos, assim como do recredenciamento de IES, os quais devem ser renovados com base em processos regulares (e reguladores) de avaliação (art. 14);

f. em maio de 1997, o MEC baixou várias portarias ministeriais, especificando requerimentos e condições para: I . a autorização de novos cursos para faculdades integradas, faculdades e institutos superiores (Port. n. 64 I); 2. credenciamento de faculdades integradas, faculdades e institutos superiores (Port. n. 640); 3. credenciamento de centros universitários (Port. n. 639) e 4. universidades (Port. n. 637). Os resultados obtidos pelas IES nas avaliações realizadas pelo MEC são parte desses requerimentos.

Pode-se argumentar, pois, que a política de avaliação do MEC não pode ser reduzida a um simples teste ("Provão") como alguns dos seus críticos costumam apontar. Com efeito, o ENC foi planejado para operar uma nova lógica da política de controle, coordenação e acompanhamento das IES pelas agências estatais reguladoras (MEC e CNE). A política de avaliação do MEC envolve manipulação de complexos e variados mecanismos reguladores que produzem impacto sobre o sistema de ensino superior como um todo. As condições estabelecidas (autorização, credenciamento e recredenciamento), a possibilidade de punição para as IES particulares (como, por exemplo, o descredenciamento), e mais a publicação dos resultados obtidos pelas IES nas avaliações de cursos e das instituições, criam juntos um poderoso instrumento de coordenação, controle e monitoramento 
que não encontram paralelos na história da educação superior brasileira. É importante notar, além disso, que tais instrumentos reforçam significativamente os chamados agentes e mecanismos do mercado educacional.

É necessário levar particularmente em consideração a magnitude dos números que caracterizam o ENC para se poder captar sua importância no contexto educacional brasileiro. Em 1996, 55.526 estudantes de 616 cursos nas áreas de administração, direito e engenharia civil foram avaliados pelo ENC. Em 1997, o ENC expandiu-se para incluir mais três cursos: engenharia química, medicina veterinária e odontologia. Isto representou a avaliação de 85.574 estudantes de 822 cursos. Mais quatro cursos (jornalismo, engenharia elétrica, letras e matemática) foram avaliados em 1998, envolvendo 142 mil estudantes de 1.710 cursos (Brasil, 1998). Em 1999, em torno de 173 mil estudantes de 2.15 I cursos foram avaliados devido à inclusão de economia, engenharia mecânica e medicina. Em julho de 2000, 18 áreas foram avaliadas, porque o ECN expande-se para incorporar agronomia, biologia, física, psicologia e química (ver Tab. I). Isto sinaliza uma nova economia de regulação e coordenação, a qual tem mudado o relacionamento entre estudantes, professores, administradores, reitores, próreitores de um lado, e do outro, os instrumentos das agências estatais para agir em relação às instituiç̧̃̃es de ensino superior.

TABELA I

NÚMERO DE CURSOS AVALIADOS PELO EXAME NACIONAL DE CURSOS 1996-1999

\begin{tabular}{lrrrr}
\hline Cursos & \multicolumn{5}{c}{ Número de cursos avaliados } \\
\hline & 1996 & 1997 & 1998 & 1999 \\
\hline Administração & 335 & 354 & 391 & 431 \\
Direito & 179 & 196 & 212 & 229 \\
Engenharia Civil & 102 & 106 & 110 & 112 \\
Engenharia Química & - & 44 & 47 & 48 \\
Medicina Veterinária & - & 37 & 39 & 43 \\
Odontologia & - & 85 & 86 & 87 \\
Engenharia Elétrica & - & - & 81 & 84 \\
Jornalismo & - & - & 84 & 92 \\
Letras & - & - & 299 & 382 \\
Matemática & - & - & - & 305 \\
Economia & - & - & - & 787 \\
Engenharia Mecânica & - & 822 & 1.710 & 2.151 \\
Medicina & 616 & & - & 81 \\
\hline Total & & - & & -10 \\
\hline
\end{tabular}

Fonte: Brasil (1998, 1999). 
De acordo com as expectativas oficiais, como mais e mais cursos serão avaliados por cada IES, isto irá constituir a avaliação da instituição como um todo. Os resultados desse procedimento de avaliação, publicados na forma de ranking por conceitos, e a sua suplementação com a avaliação das condições de oferta de cursos realizada pela SESu, constituem veículos essenciais para gerar dados que permitirão a formação de juízo de valor sobre a qualidade do ensino oferecido pelas IES. De posse dessas informações, estudantes e seus pais estarão em "melhores" condições para escolher seus cursos. Dessa forma, o governo muda o papel regulador do MEC ao incorporar as funções de "Estado avaliador" (Neave, 1988), e requer de ambos, estudantes e IES, um comportamento fundamentado nos princípios da troca, típico de um moderno mercado e da teoria dos jogos.

\section{CONSIDERAÇÕES FINAIS}

Este artigo realizou análise comparada de duas iniciativas de política de avaliação que caracterizam, respectivamente, as gestões dos ministros Murilo Hingel (1993-1994) e Paulo Renato Sousa. Argumentamos que existem divergências fundamentais nas duas políticas de avaliação. Também foram identificadas as razões que levaram o ministro Paulo Renato e sua equipe a descartar o Paiub e adotar procedimentos de avaliação que gerassem dados para informar os processos decisórios de formulação e implementação de políticas. Por isso, defendeuse aqui o argumento de que a política de avaliação implantada durante o Governo FHC foi estrategicamente programada para operar uma nova economia de regulação estatal. Isso implica dizer que a atual política de avaliação do MEC não representou simplesmente uma mudança no relacionamento entre o Governo $\mathrm{FHC}$ e as IES, mas que introduziu mudanças profundas nos mecanismos e requerimentos burocráticos e tradicionais pelos quais se dava o relacionamento entre as agências estatais e as instituições e setores do ensino superior.

De um estado de ausência de um sistema formal de avaliação no nível federal, a avaliação do ensino superior tem-se convertido em característica sistemática e regular do sistema de ensino superior brasileiro. ○ "Provão", assim como a avaliação das condições de oferta de cursos (Brasil, 1997f, 1999a), está certamente alcançando uma fase de consolidação, superando as resistências, diminuindo a hostilidade que marcou as primeiras rodadas de avaliação, e mais importante, está conquistando suporte para além das fronteiras das universidades e das instituições de ensino superior. Até 1995, não havia em operação 
nenhum procedimento de avaliação nacional e centralizado que fizesse a ponte entre credenciamento de instituições e controle da "qualidade" de ensino. $O$ princípio da avaliação, colocado em prática através do ENC e posteriormente pela avaliação das condições de oferta de cursos, inaugurou um novo estágio na história da educação superior no Brasil. A existência do ENC suscitou toda uma série de fenômenos sociais e educacionais que não podem ser ignorados. Um deles é a nova forma de legitimação da função social da educação superior que emerge da avaliação sistemática e regular.

A avaliação, segundo a retórica governamental, diz respeito à "competência, competição e controle" (Broadfoot, 1996). Estudantes e instituições de ensino têm de "provar" competência para desempenhar suas funções específicas na sociedade. No primeiro caso, como futuros profissionais habilitados e treinados e, no segundo, como instituições competentes para oferecer um serviço de qualidade. Nos dois casos, instituições e estudantes, de acordo com a política de avaliação em curso, são certificados pelo Estado. A regulação estatal (e como conseqüência, a certificação formal) funda a situação na qual indivíduos e instituições são levados

...a competir em iguais bases para demonstrar suas credenciais de competência. A situação de uma competição que é aparentemente aberta e honesta sugere que aqueles que não tenham obtido sucesso na realização das suas aspirações irão aceitar o critério de seleção racional aplicado e, portanto, suas próprias falhas. (Broadfoot, 1996, p. 10)

Este parece ser, portanto, o papel da avaliação - da participação de estudantes por um lado, e instituições de ensino superior por outro - que legitima as novas funções do MEC no ensino superior. Contudo, o MEC, ao exercitar suas funções avaliativas, passa a exercer por isso mesmo um considerável controle sobre os processos e mecanismos mediadores da interação dos diversos atores do campo do ensino superior com o objetivo de realizar suas metas. Como a interpretação oficial sugere (Sousa, 1996, e vários dos entrevistados enfatizaram este aspecto) a questão do controle - mais especificamente referida como uma conseqüência positiva da nova sistemática de recredenciamento - incorpora outros aspectos do ensino superior, dentre os quais se pode mencionar os conteúdos curriculares e o contexto institucional. Isto é particularmente interessante porque a introdução de procedimentos de avaliação (como o ENC) tem-se dado paralelamente à proposta de reforma curricular dos cursos de graduação. 
Dessa forma, pode-se introduzir um segundo aspecto da questão da legitimidade, a "expansão" - no caso brasileiro - "de comissões quase-governamentais" (Clark, 1983, p. I47), que demonstra uma nova forma de aumentar a coordenação governamental sobre as atividades da educação superior. Quando esta expansão diz respeito ao estabelecimento das funções avaliativas do Estado, coordenação e controle são inseparáveis. Daí que o papel das comissões dentro do sistema, na forma como o MEC tem definido, materializa-se como "comissões de especialistas". Dado que são definidas como especializadas, seus membros são indicados a partir de concepções de competência, conhecimento e expertise. Tais comissões de especialistas legitimam técnica e politicamente os critérios de avaliação do MEC que define de uma forma relativamente precisa o papel "técnico" das comissões. Esses dados corroboram com outras evidências, sugerindo que as mudanças observadas no sistema de ensino superior são resultados da ação sistemática do MEC que busca a redefinição do papel regulador do Estado em relação aos setores do ensino superior (Gomes, 2000).

É importante também notar que a principal estratégia usada pelo governo para implementar sua política de avaliação foi a institucionalização, via leis (o ENC e o CNE), decretos (os procedimentos constituintes do sistema nacional de avaliação do ensino superior, os centros universitários etc.) e portarias ministeriais (por exemplo, o novo Paiub). Como observa Clark:

...central para a institucionalização é o interesse disfarçado na forma. Os participantes trabalham para perpetuar uma forma que lhes serve e protege, na qual eles desenvolvem direitos percebidos como legítimos por outros, e em torno dos quais eles desenvolvem ideologias que justificam continuidade e controle. (1983, p.220)

Finalmente, o ministro Paulo Renato Sousa ( 1996 ) tem expressado que uma de suas metas de governo é desenvolver as funções avaliativas do Estado e diminuir suas funções credenciadoras. Isso parece paradoxal uma vez que já está estabelecido por evidências históricas e empíricas que o papel nuclear da avaliação de sistemas é credenciar e certificar. A análise sugere que o governo não desistiu de suas funções credenciadoras, e sim que mudou fundamentalmente os mecanismos e a lógica dos processos reguladores, agora condicionados aos resultados de avaliação. Os mecanismos burocráticos de controle que negligenciavam (ou protegiam?) uma determinada dinâmica de organização e funcionamento do sistema, que ignoravam (ou protegiam?) as missões e aspirações dos principais atores 
e setores do ensino superior foram em parte substituídos por critérios de avaliação dos resultados. A nova lógica de funcionamento do sistema de ensino superior define os agentes e mecanismos do mercado como um novo vetor coordenador do sistema, ao lado do próprio Estado, das universidades e dos professores. Segundo o MEC, as informações necessárias ao efetivo funcionamento dos mecanismos de mercado são agora geradas pelo ENC e pela avaliação das condições de oferta de cursos, e disponibilizadas pelo MEC (Inep e SESu) para o uso competitivo do cliente-cidadão (Pereira, 1998) - os usuários do sistema.

\section{REFERÊNCIAS BIBLIOGRÁFICAS}

BRASIL. Leis, decretos etc. Decreto n. 2.026, de 10 de outubro de 1996. Estabelece procedimentos para o processo de avaliação dos cursos e instituições de ensino superior. Brasília, 1996.

. Decreto n. 2.306, de 19 de agosto de 1997. Regulamenta, para o Sistema Federal de Ensino, as disposições contidas no art. 10 de Medida Provisória n. 1.477-39, de 8 de agosto de 1997, e nos arts. 16, 19, 20, 45, 46 e inc. 1², 52, parágr. único, 54 e 88 da Lei n. 9.394, de 20 de dezembro de 1996, e dá outras providências. Brasília, 1997.

. Lei n. 9.131 de 24 de novembro de 1995. Altera dispositivos da Lei n. 4.042, de 20 de dezembro de 1961, e dá outras providências. Brasília, 1995.

. Lei n. 9.394 de 20 de dezembro de 1996. Estabelece as Diretrizes e Bases da Educação Nacional. Brasília, 1996a.

BRASIL. Instituto Nacional de Estudos e Pesquisas em Educação. Exame Nacional de Cursos, 1998: síntese. Brasília: Inep, 1998.

Exame Nacional de Cursos, 1999: síntese. Brasília: Inep, 1999.

BRASIL. Ministério da Educação e Cultura. Planejamento político-estratégico 1995-1998. Brasília, maio, 1995a.

. Portaria n. 637, de 13 de maio de 1997. Dispõe sobre o credenciamento de universidades. Brasília, 1997a.

Portaria n. 639, de 13 de maio de 1997. Dispõe sobre o credenciamento de centros universitários, para o sistema federal de ensino superior. Brasília, 1997b.

. Portaria n. 640, de 13 de maio de 1997. Dispõe sobre o credenciamento de faculdades integradas, faculdades, institutos superiores ou escolas superiores. Brasília, 1997c. 
. Portaria n. 641, de 13 de maio de 1997. Dispõe sobre a autorização de novos cursos em faculdades integradas, faculdades, institutos superiores em funcionamento. Brasília, 1997d.

. Portaria n. 878, de 30 de julho de 1997. Define os procedimentos para o cumprimento do disposto no art. 12, do Decreto n. 2.207, de 15 de abril de 1997. (Revogado pelo Decreto n. 2.306.) Brasília, 1997e.

BRASIL. Ministério da Educação/Secretaria de Educação Superior. Comissão Nacional de Avaliação. Documento básico: avaliação das universidades brasileiras. Brasília: SESu, 1993.

Paiub: Programa de Avaliação Institucional das Universidades Brasileiras. Brasília: SESu, 1994.

Programa de Avaliação Institucional das Universidades Brasileiras: convite. Brasília: SESu, 1996 b.

Relatório síntese de verificação das condições de oferta de cursos de graduação. Brasília: SESu, 1999a.

Relatório síntese de verificação das condições de oferta de cursos de graduação. Brasília: SESu, $1997 f$.

BROADFOOT, P. M. Education, assessment and society. Buckingham: Open University Press, 1996.

CANTO, O. Universidades já se avaliam, diz reitor. Folha de S. Paulo, 4 nov. 1996.

CLARK, B. R. The Higher education system: academic organization in cross-national perspective. California: University of California Press, 1983

GOMES, A. M. The Cardoso government's project for highereducation: procrustean solutions in the management of change? Bristol, England, 2000. Tese (Dout.) University of Bristol, Graduate School of Education.

Política de avaliação para o sistema de ensino superior do governo FHC: parte II. (no prelo)

NEAVE, G. On the cultivation of quality, efficiency and enterprise: an overview of recent trends in higher education in Western Europe, 1986-1988. European Journal of Education, v.23, n. I/2, p.7-23, 1988.

PEREIRA, L. C. Reforma do Estado para a cidadania : a reforma gerencial brasileira na perspectiva internacional. São Paulo; Brasília: Editora 34, 1998.

SOUSA, P. R. Por uma nova universidade. Infocapes. Brasília: Capes, v.4, n. 4, 1996. 
. Prioridade à graduação. Folha de S. Paulo, 18 mar. 1998.

. Provão é dever do Estado, diz Sousa. Folha de S. Paulo, 4 nov. 1996 a.

Recebido em: novembro 200 I

Aprovado para publicação em: junho 2003 